Recepción: 10 / 06 / 2018

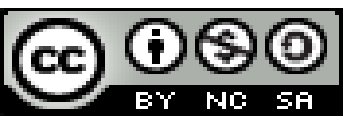

Publicación: 05 / 10 / 2018

\title{
Cultura emprendedora en las microempresas viales de la provincia del Cañar
}

\section{Entrepreneurial culture in the micro-enterprises of the province of Cañar}

\section{Cultura empreendedora nas microempresas da província de Cañar}

\author{
Juan B. Solis-Muñoz ${ }^{\mathrm{I}}$ \\ jbsolizm@ucacue.edu.ec \\ Jorge O. Quevedo-Vázquez II \\ joquevedov@ucacue.edu.ec \\ Xavier A. Mantilla-Crespo ${ }^{\text {III }}$ \\ xamantillac@ucacue.edu.ec \\ Lucía M. Neira-Neira $^{\text {IV }}$ \\ Imneiran@ucacue.edu.ec
}

\section{Correspondencia: jbsolizm@ucacue.edu.ec}

\footnotetext{
I Magister en Administración de Empresas Mención en Recursos Humanos y Marketing, Magister en Procesos Educativos Mediados por Tecnologías, Auditor, Comunicador Social, Contador Público, Ingeniero Empresarial, Locutor, Docente de la Universidad Católica de Cuenca Sede Azogues, Azogues, Ecuador.

${ }^{\text {II } M a g i s t e r ~ e n ~ A d m i n i s t r a c i o ́ n ~ d e ~ N e g o c i o s, ~ E c o n o m i s t a, ~ L i c e n c i a d o ~ e n ~ E c o n o m i ́ a ~ y ~ F i n a n z a s, ~ D o c e n t e ~ d e ~ l a ~ U n i v e r s i d a d ~ C a t o ́ l i c a ~}$ de Cuenca Sede Azogues, Azogues, Ecuador.

III Magister en Administración de Empresas Mención en Recursos Humanos y Marketing, Auditor, Contador Público, Ingeniero Empresarial, Docente de la Universidad Católica de Cuenca Sede Azogues, Azogues, Ecuador.

IV Doctora en Jurisprudencia, Magister en Desarrollo de la Inteligencia y Educación, Abogado de los Tribunales de Justicia de la Republica, Licenciada en Ciencias Jurídicas y Sociales, Profesora de Educación Media en la Especialidad de Pedagogía, Profesor de Educación Primaria-Nivel Técnico Superior, Docente de la Universidad Católica de Cuenca Sede Azogues, Azogues, Ecuador.
} 


\section{Resumen}

El presente artículo de corte no experimental con enfoque cuantitativo, de alcance exploratorio y descriptivo pretende demostrar si es posible crear una cultura de emprendimiento en base a experiencias reales promovidas por las microempresas de conservación vial en la provincia del Cañar. El universo corresponde al 100\% de los 67 trabajadores -socios en 7 micro empresas viales. El 7,46\% destinan recursos de sus ingresos provenientes de los salarios que perciben en actividades de conservación vial a emprendimiento en actividades productivas diferentes a la conservación vial. Las actividades de mayor preferencia para el emprendimiento son: crianza, desposte y comercialización de pollos alcanza $(25,23 \%)$; crianza de ganado vacuno y porcino (20,64\%). Cultivo y comercialización de hortalizas; y, de maíz (16,19\%). Sin embargo, promedio el 77,58\% no recibe apoyo técnico, financiamiento y capacitación en Emprendimiento. Tan solo un $18,57 \%$ es beneficiario de programas en la línea del análisis. Se deduce que si es factible desarrollar cultura de emprendimiento al establecer la preferencia por otras actividades de emprendimiento contando con un sostenido programa de vinculación con la sociedad de asistencia técnica y financiamiento.

Palabras clave: emprendimiento; cultura; conservación; vinculación; asistencia; financiamiento.

\section{Abstract}

The present article, whose design is non-experimental with a quantitative approach, it also has an exploratory and a descriptive scope. The main objective of this work is to demonstrate whether it is feasible to create a culture of entrepreneurship based on real experiences promoted by microcompanies of road conservation in the province of Cañar. The universe corresponds to $100 \%$ of the 67 workers-partners in seven micro-road companies. $7.46 \%$ allocate resources from their income which comes from the salaries they receive in road conservation activities to entrepreneurship in productive activities in contrast to road conservation. The most preferred entrepreneurial activities in this location are breeding, stripping and commercialization of chickens with $25.23 \%$; cattle and pigs correspond to $20.64 \%$. Cultivation and marketing of vegetables and corn reach $16.19 \%$. However, on average $77.58 \%$ do not receive technical support, financing and training in entrepreneurship. Only $18.57 \%$ are beneficiaries of programs in the line of analysis. It is inferred that it is feasible to develop a culture of entrepreneurship by 
establishing a preference for other entrepreneurial activities, with a sustained program of linkage with the society of technical assistance and financing.

Key words: entrepreneurship; culture; conservation; linkage; assistance; financing.

\section{Resumo}

Este artigo não experimental de abordagem quantitativa, exploratório e descritivo, visa demonstrar se é possível criar uma cultura de empreendedorismo baseada em experiências reais promovidas por microempresas de conservação viária na província de Cañar. $\mathrm{O}$ universo corresponde a 100\% dos 67 trabalhadores-parceiros em 7 empresas de microestradas. 7,46\% alocam recursos de sua renda dos salários que recebem em atividades de conservação de estradas para o empreendedorismo em atividades produtivas além da conservação de estradas. As atividades mais preferidas para o empreendimento são: criação, desmatamento e comercialização de frangos (25,23\%); criação de bovinos e suínos (20,64\%). Cultivo e comercialização de vegetais; e, de milho (16,19\%). No entanto, em média, 77,58\% não recebem apoio técnico, financiamento e treinamento em Empreendedorismo. Apenas 18,57\% são beneficiários de programas na linha de análise. Segue-se que é possível desenvolver uma cultura de empreendedorismo, estabelecendo uma preferência por outras atividades empreendedoras, com um programa sustentado de ligação com a sociedade de assistência técnica e financiamento.

Palavras chave: empreendedorismo; cultura; conservação; ligação; assistência; financiamento.

\section{Introducción}

El abordaje de la cultura del emprendimiento e innovación se asume bajo el presupuesto histórico de creación del Ministerio de Obas Públicas, hoy bajo la denominación de Ministerio de Transporte y Obras Públicas MTOP. Según datos oficiales consignados en la página institucional se precisa que: "con el objetivo de ejecutar obras viales y de comunicaciones que permitan impulsar el fomento y desarrollo económico y social del Ecuador, el 9 de julio de 1929 se creó el Ministerio de Obras Públicas y Comunicaciones con las siglas de MOP, en el gobierno de Isidro Ayora. Es revelador precisar que la cartera de Estado en sus inicios tuvo competencias en el ámbito de la agricultura, comercio y el fomento de la producción agrícola e industrial. Siendo 
esencial las actividades de estudios, construcción, explotación, conservación y financiamiento de las obras públicas.

En la línea de la publicación oficial del Departamento de Comunicación Social de la Matriz (2018) se menciona que también estuvo a cargo de esta institución la administración de las líneas postales, telegráficas y telefónicas. Así como la instalación de estaciones radiotelegráficas del Estado. Se contó con la Dirección General de Obras Públicas con las direcciones de Agricultura, Correos y Telégrafos. La fiscalización de las obras ejecutadas por contrato y el estudio de reformas de legislación relacionadas al agro, el agua y los bosques estuvo bajo la tutela del Ministerio de Obras Públicas. Más adelante hacia 1992 se creó el departamento de Impactos Ambientales. Mediante Decreto Ejecutivo No. 053, el 15 de enero de 2007 se cambió la estructura como Ministerio de Transporte y Obras Públicas con cuatro subsecretarías.

El modelo de mantenimiento vial mediante la activación de las microempresas viales cruza por el entendimiento de las tensiones teóricas que entorno al fenómeno que se investiga existe. La primera aproximación tiene que ver en la línea de pensamiento de González (2005) las implicaciones económicas que conlleva definir a la microempresa:

En él se argumenta que el principal problema que presenta la definición se deriva de que el término micro, al igual que los términos pequeño y mediano, se usa para expresar dimensión o tamaño. Algunas definiciones cualitativas propuestas por diversos autores, presentan la indeterminación de que pueden ser aplicables a los demás tamaños de empresas. Se concluye que el término micro empresa da cuenta de empresas muy pequeñas en relación a las demás y su desarrollo está asociado a factores que no necesariamente están condicionados a su tamaño.

En la actualidad el significado de las microempresas viales varía desde el punto de vista en que se encuentre dentro de los ámbitos legales del país o de la localidad, también depende del alcance que posea la misma, es decir, varía de acuerdo a los factores que se relacionen y en el ámbito en que se vea este factor:

Las microempresas viales son entidades jurídicas, legalmente constituidas, que realizan de manera permanente y adecuada las labores de mantenimiento rutinario de los caminos secundarios y vecinales que les son asignados. Son promovidas por la autoridad responsable de la conservación vial, dentro de las poblaciones que habitan en las inmediaciones de las vías que han 
sido elegidas para ser sometidas al sistema de mantenimiento rutinario, Salomón \& González (2003).

Esto quiere decir que las microempresas viales son creadas como una entidad por un conjunto de pobladores residentes a la zona en la cual está efectuada la obra vial, con el fin de que los poblados de bajos recursos creen sus propias fuentes de trabajo para así mejorar su economía y a la vez dar el mantenimiento vial correspondiente.

Desde otro contexto se puede definir en sí a la microempresa la cual es una entidad que puede ser unipersonal y que pueda operar ya sea legitima o ilegítimamente, es por ello que Pazmiño (2007) afirma lo siguiente:

Las microempresas son consideradas pequeñas unidades económicas sociales, producto de los procesos de organización y experimentación social relacionadas con las actividades económicas a pequeña escala. Estas unidades presentan un modo coherente y racional de organizar la actividad económica y se pueden comparar a empresas o negocios de pequeño tamaño que se presentan en algunos casos como: empresas familiares, cooperativas, empresas de servicios, talleres artesanales y comercio. Todas las microempresas están constituidas por personas, donde el número puede ser muy variable, pero cada una aporta diferentes recursos y forman una sola unidad económica de trabajo y de gestión.

Entonces se puede decir que la creación de microempresas en la sociedad y más si son es zonas que poseen una economía baja, son de gran ayuda tanto para la población de ese sector como para el progreso de la misma, ya que en muchos de los casos estas organizaciones de microempresas son conformadas por un cierto número de integrantes familiares, de tal manera se genera un comercio en el sector.

En opinión de Texis et al. (2011) al abordar el tema Aprendizaje en microempresas en Baja California, expone la potencia micro empresarial y la capacidad generadora de empleo en contraposición con la mediana y gran empresa cuyo efecto en relación al empleo, más bien es marginal: 
La estructura empresarial en México se ha caracterizado por la presencia de microempresas, con énfasis en las conformadas por dos empleados como máximo, representando, en 2008, 65\% de los establecimientos y $18 \%$ del empleo. Esto las convierte en un elemento sensible para equilibrar procesos de equidad y mejorar los niveles de bienestar de sus integrantes. En este trabajo se analiza el desempeño de un grupo de 227 microempresas del estado de Baja California. Para ello se ha considerado una aplicación práctica del modelo de curva de aprendizaje relacionado con los rendimientos a escala que exhiben. Los resultados indican que en $48 \%$ de los casos hay evidencias de procesos de aprendizaje y $58 \%$ presentan rendimientos crecientes a escala. Lo anterior permite evaluar el potencial de desarrollo de las microempresas y podría encaminar el diseño y puesta en marcha de programas que fomenten dinámicas de aprendizaje y su consolidación en el mercado.

Vemos entonces en criterio de Neira (2006) que las microempresas tienen una importante contribución al crecimiento económico, la competitividad, la innovación y la creación de empleo en los países latinoamericanos. "Paradójicamente, pese a la gran importancia de las microempresas para las economías de América Latina, es poco lo que se conoce, en detalle, de la manera en que se les investiga".

\section{Así, la legislación ecuatoriana señala en el artículo 53 del Código Orgánico de la Producción, Comercio e Inversiones:}

La micro, pequeña y mediana empresa es toda persona natural o jurídica que, como una unidad productiva, ejerce una actividad de producción, comercio y/o servicios y que cumple con el número de trabajadores y valor bruto de las ventas anuales, señalados para cada categoría.

En tal sentido, el artículo 106 del Reglamento a la Estructura e Institucionalidad de Desarrollo Productivo de la Inversión y de los Mecanismos e Instrumentos de Fomento Productivo, expedido mediante Decreto Ejecutivo número 757, publicado en el Registro Oficial número 450 del 17 de mayo del 2011, reformado mediante Decreto Ejecutivo número 218 del 22 de noviembre de 2017, se establece:

Micro empresa: Es aquella unidad productiva que tiene entre 1 a 9 trabajadores y un valor de ventas o ingresos brutos anuales iguales o menores trescientos mil (US \$300.000,00).

En este contexto las microempresas viales constituyen un modelo de gestión para el mantenimiento rutinario y periódico de la red estatal del Ecuador, gestionadas no solamente 
desde el Ministerio de Transporte y Obras Públicas, sino también desde las prefecturas provinciales en la competencia establecida en la Constitución de la República (2008) en el artículo 263, numeral 2 Planificar, construir y mantener el sistema vial de ámbito provincial, que no incluya las zonas urbanas. En concordancia el artículo 42 literal b, del Código Orgánico de Organización Territorial, Autonomía y Descentralización.

En efecto, el Informe Micro empresas Viales en el Azuay, se trata de un estudio sobre las micro empresas viales como un sistema alternativo de mantenimiento vial en la provincia del Azuay. El periodo de análisis es el 2000 al 2006 en el que se destaca:

Las instituciones estatales como los Gobiernos Provinciales, Alcaldías, Juntas Parroquiales, ONGs, FISE, podrían ampliar su rol de proyectos dejando de lado su estado paternalista, vinculando el servicio de mano de obra no calificada y la transferencia de recursos, atacando el problema del alcoholismo, el desempleo y por sobre todo la emigración.

La línea documental sostiene que el mantenimiento vial rutinario es un proyecto sostenible ya que su costo es razonable, optimizando la relación costo beneficio, una labor que se ejecuta en equipo posibilitando el fortalecimiento de las capacidades y potenciales de las comunidades beneficiarias.

Ahora bien, siendo la dimensión de la seguridad vial un indicador de innegable importancia medido desde la siniestralidad en las vías. Según el semanario El Heraldo del Cañar (2018) “53,3\% es el porcentaje de incremento en accidentes de tránsito en la provincia del Cañar en los primeros meses del año 2018, en relación al mismo periodo del 2017”. Así, en opinión de Tencio (2008) en el abordaje de una alternativa para la formación vial, tomando en cuenta los accidentes de tránsito en Costa Rica, precisa:

Esta epidemia como la llama la OMS (Organización Mundial de la Salud) ha sido desde ya hace décadas una enfermedad silenciosa, donde no se encuentran soluciones eficaces que acaben con tantas secuelas que deja a su paso, a pesar del esfuerzo de muchas instituciones del país. Es así como se pretende desarrollar una iniciativa desde una perspectiva que oriente la búsqueda de soluciones, desde las raíces de nuestra cultura por medio de una formación integral continua desde edades tempranas. Esta tarea sin lugar a dudas le corresponde a todos los que somos partícipes, pero la visión y misión de formar ciudadanos conscientes de sus derechos, sin olvidar sus deberes en armonía con lo que le rodea desde principios que demuestran una sociedad más 
responsable y segura, le corresponde al sistema educativo costarricense, en conjunto con las diversas entidades que de una y otra forma son parte de esta situación. Esto con el objetivo de encontrar en la educación continua y sistemática, una herramienta efectiva que a mediano o largo plazo logre disminuir las estadísticas de muertes en carreteras, por la negligencia o error humano, causa de mayor incidencia en los accidentes de tránsito, por medio de una formación en y para una cultura vial, cuya política e ideología sea respetar la vida en la búsqueda del bienestar común. Con el antecedente, corresponde situar en el contexto de la provincia del Cañar, país Ecuador, a las microempresas viales bajo el mando del Ministerio del Transporte y Obras Públicas, desde su constitución legal y operativa, radio de acción y las dimensiones y variables analizadas a la luz del estudio de campo. Se intenta mirar de qué manera se ha logrado introducir la cultura del emprendimiento a otras actividades productivas con los propios socios y las posibilidades generación de empleo productivo. Desde luego después de conocer el impacto de las microempresas viales en las actividades propias de sus constitución y razón de ser.

En rigor, el Ministerio del Transporte y Obras Públicas, Subsecretaría Regional 6, emitió las Resoluciones Nros: 001-MTOP-SUBREG6-PJ-16; 002-MTOP-SUBREG6-PJ-16; 03-PJ-15; 004PJ-12; 01-DPC-06; 03-DPC-2006; 014-MTOP-SUBZ6-PJ-17, considerando:

Que, de conformidad con lo prescrito en el numeral 13 del Art. 66 de la Constitución Política de la República, el Estado Ecuatoriano reconoce y garantiza a los ciudadanos el derecho de asociarse, reunirse y manifestarse en forma libre y voluntaria. Que, el Título XXX, Libro I del Código Civil vigente, faculta la concesión de personería jurídica a corporaciones y fundaciones, como organizaciones de derecho privado, con la finalidad social y sin fines de lucro. Que, con Decreto Ejecutivo No. 16, publicado en el Registro Oficial Suplemento No. 19, del 20de junio de 2013, se expidió el Reglamento para el funcionamiento del sistema unificado de información de las organizaciones sociales y ciudadanas, posteriormente las reformas al Reglamento para la aprobación de estatutos, reformas y codificaciones, liquidación y disolución, y registro de socios y directivas, de las organizaciones previstas en el Código Civil y en las leyes especiales. Que, mediante Acuerdo Ministerial No. 020 de 29 de marzo de 2016, publicado en el Registro Oficial No. 252 del 28 de abril de 2016, y reformado mediante Acuerdo Ministerial No. 001 del 19 de julio de 2006, publicado en el Registro Oficial No. 325 del 1 de agosto del 2006, el señor Ministro de Obras Públicas y Comunicaciones delegó a los subsecretarios y directores 
provinciales de Obras Públicas, la facultad de otorgar personería jurídica a las asociaciones de conservación vial (...) Que, en el Estatuto Orgánico de Gestión Organizacional por Procesos, la reforma aprobada por el Ministerio de Relaciones Laborales, con su respectiva codificación numeral 4, Procesos Desconcentrados, 4.1 Subsecretaría Zonal del Transporte y Obras Públicas, constan como atribuciones y responsabilidades del señor Subsecretario, en el numeral 9, señale textualmente: Aprobar la conformación y otorgar personería jurídica de las organizaciones y asociaciones de conservación vial, con plena observancia de las normas legales y reglamentarias vigentes (microempresas) de los diferentes modos del transporte.).

El abordaje introductorio permite revisar los antecedentes de la política pública del ente Rector del Transporte y Obras Públicas en el Ecuador, al insertar a las microempresas viales como modelo de gestión vial en el mantenimiento rutinario a la red estatal. Se espera fomentar la cultura emprendedora como un plus innovador a la propuesta teórica. La cultura emprendedora como una experiencia vivida con las microempresas viales en la provincia del Cañar se enlaza con los hallazgos del trabajo de campo.

\section{Importancia del Problema}

La presente investigación responde al núcleo problémico que consiste en determinar si las microempresas viales generan cultura emprendedora en otros sectores productivos de la provincia del Cañar. Tomando en cuenta la incidencia del desempleo y subempleo en la población económicamente activa. Si existe una política pública orientada a fomentar la cultura emprendedora en la línea de las microempresas viales, es necesario entonces la búsqueda de posibles consecuencias en los emprendimientos de la economía popular y solidaria. El estudio se desarrolla en la provincia del Cañar y está atado a la red estatal de competencia del gobierno central mediante las instancias desconcentradas del Ministerio del Transporte y Obras Públicas. En realidad, los estudios de carácter empírico que sobre la temática de microempresas viales se han escrito están sujetos a nuevos aportes teóricos. La generación de un enfoque situado que expresa en los datos cuantitativos los niveles de impacto de las unidades económicas en las competencias de mantenimiento rutinario y periódico en la red vial estatal. 


\section{Metodología}

El presente apartado evidencia la metodología empleada para arribar a los hallazgos expuestos en párrafos que anteceden. En la línea de pensamiento de Sampieri (2008) en el tratado de Metodología de la Investigación, el estudio es de alcance exploratorio y descriptivo. Tiene un enfoque cuantitativo. De corte no experimental. Parte del siguiente problema de investigación ¿Es posible generar cultura de emprendimiento en base a la experiencia de las microempresas de conservación vial en la provincia del Cañar?

De análisis y de síntesis: Para describir los procesos de diseño, integración y aplicación de criterios y herramientas utilizadas en la construcción de los factores determinantes a estudiar.

De análisis histórico y de análisis lógico: Se aplica el estudio de las evidencias empíricas obtenidas en el trabajo de campo en 7 micros- empresas de conservación vial en la provincia del Cañar.

De enfoque sistémico: Se aplicó 67 encuestas al 100\% de socios (trabajadores) de las 7 microempresas de conservación vial situadas en la provincia del Cañar.

El instrumento de recolección de datos fue diseñado partiendo de la categoría de estudio: cultura emprendedora a partir de la experiencia de las microempresas viales en la provincia del Cañar. Considera variables que van de menos a más con relación al problema de investigación.

Métodos estadísticos: Recolección, tabulación y análisis de datos, con el empleo de las herramientas de apoyo: Excel y Spss.

\section{Resultados}

Con el antecedente, el Ministerio del Transporte y Obras Públicas, Subsecretaría Regional 6, procede en el artículo 1 de las Resoluciones Administrativas aprobar la conformación y conceder Personería Jurídica a las siguientes Asociaciones de Conservación Vial: Zhoray, Matapín, Las Américas, San Antonio de Paguancay, La Primavera, Sageo, Nuevo Javín, de acuerdo con la Tabla Nro. 1.

Son 7 microempresas viales y en total 67 socios emprendedores con la calidad laboral de trabajadores dedicados a laborar en las vías a cargo de Ministerio del Transporte y Obras Públicas, tanto en la vía estatal Panamericana como en la vía colectora Azogues- MatramaMazar. La iniciativa surge de los actores de la economía popular y solidaria, tal como se 
desprende de la motivación expresada en las Resoluciones Administrativas que dan inicio legal a las unidades productivas:

El trabajo de campo se ha trabajado con el $100 \%$ de los socios de la totalidad de las microempresas viales. La variable Tiempo de Trabajo en las unidades productivas tiene el siguiente comportamiento:

La tabla muestra la concentración del tiempo de trabajo de los socios en las unidades productivas de conservación vial en la provincia del Cañar, en los rangos de 0 a 1 años; y, de 2 a 5 años lo que corrobora las fechas de creación y la continuidad operativa de las microempresas viales.

La Actividades de las Micro Empresas de Conservación Vial en la provincia del Cañar, son: Limpieza de cunetas, limpieza de alcantarillas, limpieza de malezas, limpieza de derrumbes que corroboran la finalidad de creación de las microempresas viales establecidas en las Resoluciones Administrativas. Se cuenta con las herramientas indispensables para la operación: Palas, picos, machetes, carretillas, motosierra, maquinaria pequeña, botas y poncho de caucho, ropa reflectiva, casco de seguridad.

La variable Salario Percibido (V2) se muestra en la Tabla Nro. 3 y se ha establecido, tomando en cuenta el piso que es un salario básico unificado para el 2018, en 3 rangos: De 386 a 400 dólares; 401 a 600 dólares; 601 dólares en adelante.

El salario percibido por los trabajadores (socios) de las microempresas viales en la provincia del Cañar, se encuentra mayormente concentrado en los rangos: De 386 a 400 dólares; y, 401 a 600 dólares, siendo apenas un 29\% de unidades productivas que muestran salarios en el rango de 601 dólares en adelante.

La variable Destino del Salario (V3) tiene el propósito de determinar las actividades a las que se destinan los recursos mensuales que perciben los emprendedores de las micro empresas de conservación vial en la provincia del Cañar y que básicamente se proponen: Actividades de Emprendimiento; Créditos en Instituciones Financieras; Gasto y Ahorro Familiar; y, Otros, se muestra en la Tabla Nro. 4.

Del 100\% (7) de las micro empresas viales, el (7,46\%) promedio, destinan recursos de sus ingresos provenientes de los salarios que perciben en actividades de conservación vial, a emprendimiento. Mientras que la mayor parte del ingreso está destinado al gasto y ahorro familiar $(83,80 \%)$ promedio; y, pago de créditos $(8,74 \%)$ promedio. A priori, si bien el gasto y 
ahorro familiar sumado al pago de créditos concentran promedio el 92,54\% del ingreso. Sin embargo, existen indicios de cultura de emprendimiento que podría eventualmente potenciarse con estrategias de apoyo y fortalecimiento.

De hecho, el $100 \%$ se considera un emprendedor. Ahora el propósito de la investigación es conocer a más de emprendimiento en conservación vial que es la unidad de análisis, en qué otras actividades productivas están emprendiendo o les gustaría emprender. Se dieron las alternativas que se muestran en la Tabla Nro. 5, Variable Actividades Productivas de Emprendimiento (V4) y que básicamente son: Cultivo y comercialización de hortalizas; cultivo y comercialización de papas; cultivo y comercialización de maíz; producción y comercialización de leche; Industrialización de lácteos; crianza, desposte y comercialización de pollos; crianza, desposte y comercialización de cuyes; crianza de ganado vacuno y porcino; granjas integrales; emprendimiento de turismo; y, emprendimientos de alimentación y bebida.

Del análisis promedio se desprende que la crianza, desposte y comercialización de pollos alcanza un $25,23 \%$ de aceptación de emprendimiento, seguido por crianza de ganado vacuno y porcino con un 20,64\%. Cultivo y comercialización de hortalizas; y, de maíz obtienen un 16,19\%. Además, la provincia del Cañar tiene ventajas comparativas en el campo del turismo. Sin embargo, tan solo el 9,21\% esperan emprender en este sector de la economía.

Con la intención de incidir en la política pública respecto a los programas de apoyo técnico y financiamiento por parte de las instituciones con competencia; y, en el caso de las Instituciones de Educación Superior (IES) las funciones sustantivas de investigación y vinculación con la sociedad con programas de capacitación. Se indagó la variable Apoyo Técnico, Financiamiento y Capacitación en Emprendimiento (V5) cuyos resultados se muestran en la Tabla Nro. 6.

Promedio el 77,58\% de la unidad de análisis no recibe Apoyo Técnico, financiamiento y Capacitación en Emprendimiento. Tan solo un 18,57\% dice ser beneficiario de programas en la línea del análisis.

El equipo investigador indaga en la unidad de análisis el propósito de emprendimiento, dando al menos tres categorías de respuestas que en valores promedio son los siguientes: Hacer dinero $(52,55 \%)$; generar empleo $(42,21 \%)$; y, crear una cultura emprendedora $(5,24 \%)$. 


\section{Discusión}

En este apartado es preciso hacer señalamientos comparados entre los hallazgos de la presente investigación y los estudios realizado en México en el artículo Aprendizaje en microempresas de Baja California, por los investigadores Texis, M. et al. (2011), donde la estructura empresarial se ha caracterizado por la presencia de microempresas, con énfasis en las conformadas por dos empleados como máximo, representando, en 2008, 65\% de los establecimientos y el 18\% del empleo. Esto las convierte en un elemento sensible para equilibrar procesos de equidad y mejorar los niveles de bienestar de sus integrantes. En el trabajo comparado se analiza el desempeño de un grupo de 227 microempresas del estado de Baja California. Para ello se ha considerado una aplicación práctica del modelo de curva de aprendizaje relacionado con los rendimientos a escala que exhiben. Los resultados indican que en $48 \%$ de los casos hay evidencia de procesos de aprendizaje y $58 \%$ presenta rendimientos crecientes a escala. Lo anterior permite evaluar el potencial de desarrollo de las microempresas y podría encaminar el diseño y puesta en marcha de programas que fomenten dinámicas de aprendizaje y su consolidación en el mercado.

En la provincia del Azuay también aparece un estudio sobre microempresas piloto. Se inician en dos cantones de diferente conformación física, la una se encuentra en el cantón Girón con una extensión de $25 \mathrm{Kms}$ comprende desde la parroquia Lentag- La Asunción- hasta el cantón San Fernando cuyo mantenimiento lo realizan 12 personas y la otra situada en un cantón sur oriental Sígsig. Inicia desde la parroquia Cuchil hasta la parroquia Ludo con una extensión de 25 Kilómetros. Mantenimiento que lo realizan 12 personas, estas vías fueron seleccionadas primeramente por la ubicación, luego por el flujo vehicular, número de comunidades beneficiarias.

Al cabo de dos años se realiza la evaluación técnica y social de las dos microempresas que son manejadas por el género masculino, la que se encuentra ubicada en el cantón Sígsig no tiene ningún problema en todas las labores de mantenimiento por lo que se vuelve a realizar un nuevo contrato, pero la que se encuentra en el cantón Girón y San Fernando tiene problemas de carácter técnico no justifican en su totalidad el contrato establecido, pero también influye la parte política, la actuación del presidente de la Junta Parroquial da informes negativos con el afán de reestructurar con socios nuevos cuyo listado es un compromiso adquirido en su campaña. 
Al cabo de dos años las fuerzas vivas de los dos cantones reconocen que la microempresa era la alternativa para mantener en condiciones de transitabilidad y bajo algunos compromisos se vuelve a contratar a los seleccionados y capacitados para la tarea de mantenimiento, la primera se encuentra realizando estas labores durante seis años mientras que la segunda tiene ya cuatro años de funcionamiento sin ningún problema y detectando en ambas un ahorro del $70 \%$ mediante manejo con microempresas a diferencia de las que se maneja en forma periódica con el equipo caminero, se ha mantenido el mismo personal, sin descuidar la parte social y técnica que es la que se motiva a seguir en las tareas, se les han manejado dentro de una cultura empresarial y asociativa sin descuidar el recurso humano que se ha fomentado una integración comunitaria.

\section{Conclusión}

Las conclusiones son reflexiones finales, en espacios de tensiones o territorios de disputa, a las que se arriba luego de un sostenido y sólido proceso de búsqueda de inquietudes teóricas así como la derivación de hallazgos de las aplicaciones de campo.

\section{Desde lo teórico:}

El modelo de mantenimiento vial mediante la activación de las microempresas viales cruza por el entendimiento de las tensiones teóricas que entorno al fenómeno que se investiga existe;

Al abordar el tema Aprendizaje en microempresas en Baja California, expone la potencia micro empresarial y la capacidad generadora de empleo en contraposición con la mediana y gran empresa cuyo efecto en relación al empleo, más bien es marginal;

Las microempresas tienen una importante contribución al crecimiento económico, la competitividad, la innovación y la creación de empleo en los países latinoamericanos

Desde el problema de investigación: ¿Es posible generar cultura de emprendimiento en base a la experiencia de las microempresas de conservación vial en la provincia del Cañar?

Del $100 \%$ (7) de las micro empresas viales, el $(7,46 \%)$ promedio de sus socios - trabajadores (67), destinan recursos de sus ingresos provenientes de los salarios que perciben en actividades de conservación vial, a emprendimiento en actividades productivas diferentes a la conservación vial. Desde los hallazgos: 
La concentración del tiempo de trabajo de los socios en las unidades productivas de conservación vial en la provincia del Cañar, en los rangos de 0 a 1 años; y, de 2 a 5 años lo que corrobora las fechas de creación y la continuidad operativa de las micro empresas viales;

El salario percibido por los trabajadores (socios) de las micro empresas viales en la provincia del Cañar, se encuentra mayormente concentrado en los rangos: De 386 a 400 dólares; y, 401 a 600 dólares, siendo apenas un 29\% de unidades productivas que muestran salarios en el rango de 601 dólares en adelante;

La mayor parte del ingreso está destinado al gasto y ahorro familiar $(83,80 \%)$ promedio; y, pago de créditos $(8,74 \%)$ promedio. A priori, si bien el gasto y ahorro familiar sumado al pago de créditos concentran promedio el 92,54\% del ingreso. Sin embargo, existen indicios de cultura de emprendimiento que podría eventualmente potenciarse con estrategias de apoyo y fortalecimiento;

Del análisis promedio se desprende que la crianza, desposte y comercialización de pollos alcanza un $25,23 \%$ de aceptación de emprendimiento, seguido por crianza de ganado vacuno y porcino con un 20,64\%. Cultivo y comercialización de hortalizas; y, de maíz obtienen un 16,19\%. Además, la provincia del Cañar tiene ventajas comparativas en el campo del turismo. Sin embargo, tan solo el 9,21\% esperan emprender en este sector de la economía;

Promedio el 77,58\% de la unidad de análisis no recibe Apoyo Técnico, financiamiento y Capacitación en Emprendimiento. Tan solo un 18,57\% dice ser beneficiario de programas en la línea del análisis.

El equipo investigador indagó en la unidad de análisis el propósito de emprendimiento, dando al menos tres categorías de respuestas que en valores promedio son los siguientes: Hacer dinero $(52,55 \%)$; generar empleo $(42,21 \%)$; y, crear una cultura emprendedora $(5,24 \%)$.

\section{Referencias Bibliográficas}

García, R. (2017). Taller de Metodología de la Investigación Científica. Cuenca - Ecuador; González, T. (2005). Problemas en la definición de la microempresa. Revista Venezolana de Gerencia. Vol. 10, núm. 31, julio- septiembre. Universidad del Zulia; 
Neira, F. (2006). Elementos para el estudio de la microempresa latinoamericana. Revista de Estudios Latinoamericanos, núm. 43, pp. 153-174. Centro de Investigaciones sobre América Latina y el Caribe. Distrito Federal, México;

Pazmiño, P. (2007). La microempresa en la ejecución de obra pública en el Ecuador. Obtenido de La microempresa en la ejecución de obra pública en el Ecuador: http://repositorio.uasb.edu.ec/bitstream/10644/2204/1/T0516-MDE-Pazmi\%C3\%B1o-

La\%20microempresa.pdf;

Sampieri, R. H., Collado, C. F., Lucio, P. B., \& Pérez, M. D. L. L. C. (1998). Metodología de la investigación (Vol. 1). México: Mcgraw-hill;

Salomón, E., \& González, M. (noviembre de 2003). Mantenimiento Rutinario de Caminos con Microempresas. Obtenido de Mantenimiento Rutinario de Caminos con Microempresas: http://www.ilo.org/public/spanish/employment/recon/eiip/download/mcrmanpro.pdf

Sabino, C. (1992). El Proceso de Investigación. Buenos Aires- Argentina;

Serbino. M. (2017). Memoria conferencia sobre funciones sustantivas de la Universidad. Cuenca - Ecuador;

Tencio, C. (2008). Una alternativa para la formación vial. Educación, vol. 32, núm. 1, pp. 13-26. Universidad de Costa Rica. San Pedro, Montes de Oca, Costa Rica;

Texis Flores, Michelle; Mungaray Lagarda, Alejandro; Ramírez Urquidy, Martín; Ramírez Angulo, Natanael (2011). Aprendizaje en micro empresas de Baja California. Estudios Fronterizos, vol. 12, núm. 23, enero-junio, pp. 95-116, Universidad Autónoma de Baja California. Mexicali, México. 


\section{Anexos}

Tabla Nro. 1 Microempresas viales de la provincia del Cañar

\begin{tabular}{|c|l|l|c|}
\hline Número & Razón Social & Ubicación & $\begin{array}{c}\text { Número de } \\
\text { Socios }\end{array}$ \\
\hline 1 & Zhoray & Parroquia Rivera, cantón Azogues & 10 \\
\hline 2 & Matapín & Parroquia Taday, cantón Azogues & 9 \\
\hline 3 & Las Américas & $\begin{array}{l}\text { Parroquia Pancho Negro, cantón La } \\
\text { Troncal }\end{array}$ & 10 \\
\hline 4 & San Antonio de Paguancay & $\begin{array}{l}\text { Parroquia San Antonio de Paguancay, } \\
\text { cantón Cañar }\end{array}$ & 10 \\
\hline 5 & La Primavera & $\begin{array}{l}\text { Parroquia Pancho Negro, cantón La } \\
\text { Troncal }\end{array}$ & 9 \\
\hline 6 & Sageo & Parroquia Sageo, cantón Biblián & 9 \\
\hline 7 & Nuevo Javín & Parroquia Ducur, cantón Cañar & 10 \\
\hline & & & 67 \\
\hline
\end{tabular}

Fuente: Solis, Quevedo, Mantilla, Neira. Ecuador, 2018

Tabla Nro. 2 V1: Tiempo de Trabajo en las Micro Empresas Viales

\begin{tabular}{|l|c|c|c|}
\hline Razón Social & $0-1$ años & $2-5$ años & $\begin{array}{c}\text { De 6 años en } \\
\text { adelante }\end{array}$ \\
\hline Zhoray & $40,00 \%$ & $40,00 \%$ & $20,00 \%$ \\
\hline Matapín & $33,33 \%$ & $55,56 \%$ & $11,11 \%$ \\
\hline Las Américas & $90,00 \%$ & $10,00 \%$ & $0,00 \%$ \\
\hline San Antonio de Paguancay & $90,00 \%$ & $10,00 \%$ & $0,00 \%$ \\
\hline La Primavera & $22,00 \%$ & $66,67 \%$ & $11,11 \%$ \\
\hline Sageo & $0,00 \%$ & $33,34 \%$ & $66,66 \%$ \\
\hline Nuevo Javín & $60,00 \%$ & $40,00 \%$ & $0,00 \%$ \\
\hline
\end{tabular}

Fuente: Solis, Quevedo, Mantilla, Neira. Ecuador, 2018

Tabla Nro. 3 V2: Salario Percibido

\begin{tabular}{|l|c|c|c|}
\hline Razón Social & 386 a 400 dólares & 401 a 600 dólares & $\begin{array}{c}601 \text { dólares en } \\
\text { adelante }\end{array}$ \\
\hline Zhoray & $10 \%$ & $20 \%$ & $70 \%$ \\
\hline Matapín & $0,00 \%$ & $100 \%$ & $0,00 \%$ \\
\hline Las Américas & $80 \%$ & $20 \%$ & $0,00 \%$ \\
\hline San Antonio de Paguancay & $10 \%$ & $20 \%$ & $70 \%$ \\
\hline La Primavera & $0,00 \%$ & $100 \%$ & $0,00 \%$ \\
\hline Sageo & $0,00 \%$ & $100 \%$ & $0,00 \%$ \\
\hline Nuevo Javín & $0,00 \%$ & $100 \%$ & $0,00 \%$ \\
\hline
\end{tabular}

Fuente: Solis, Quevedo, Mantilla, Neira. Ecuador, 2018 
Tabla Nro. 4 V3: Salario Percibido

\begin{tabular}{|l|c|c|c|c|}
\hline Razón Social & Emprendimiento & Pago de créditos & $\begin{array}{c}\text { Gasto y ahorro } \\
\text { familiar }\end{array}$ & Otros \\
\hline Zhoray & $20 \%$ & $10 \%$ & $70 \%$ & $0,00 \%$ \\
\hline Matapín & $0,00 \%$ & $0,00 \%$ & $100 \%$ & $0,00 \%$ \\
\hline Las Américas & $0,00 \%$ & $20 \%$ & $80 \%$ & $0,00 \%$ \\
\hline San Antonio de Paguancay & $10 \%$ & $20 \%$ & $70 \%$ & $0,00 \%$ \\
\hline La Primavera & 22,23 & $11,11 \%$ & $66,66 \%$ & $0,00 \%$ \\
\hline Sageo & $0,00 \%$ & $0,00 \%$ & $100 \%$ & $0,00 \%$ \\
\hline Nuevo Javín & $0,00 \%$ & $0,00 \%$ & $100 \%$ & $0,00 \%$ \\
\hline Valores promedio & $7,46 \%$ & $8,74 \%$ & $83,80 \%$ & $0,00 \%$ \\
\hline
\end{tabular}

Fuente: Solis, Quevedo, Mantilla, Neira. Ecuador, 2018

Tabla Nro. 5 V4: Actividades Productivas de Emprendimiento

\begin{tabular}{|l|c|c|c|c|c|c|c|c|}
\hline Actividades productivas & Zhoray & Matapín & $\begin{array}{c}\text { Las } \\
\text { Américas }\end{array}$ & $\begin{array}{c}\text { S. A. } \\
\text { Paguancay }\end{array}$ & $\begin{array}{c}\text { La } \\
\text { Primavera }\end{array}$ & Sageo & $\begin{array}{c}\text { Nuevo } \\
\text { Javín }\end{array}$ & Promedio \\
\hline $\begin{array}{l}\text { Cultivo y comercialización } \\
\text { de hortalizas }\end{array}$ & $10 \%$ & $22,23 \%$ & $40 \%$ & $10 \%$ & $0,00 \%$ & $11,11 \%$ & $20 \%$ & $16,19 \%$ \\
\hline $\begin{array}{l}\text { Cultivo y comercialización } \\
\text { de papas }\end{array}$ & $0,00 \%$ & $11,11 \%$ & $0,00 \%$ & 0,00 & $0,00 \%$ & $0,00 \%$ & $0,00 \%$ & $1,59 \%$ \\
\hline $\begin{array}{l}\text { Cultivo y comercialización } \\
\text { de maíz }\end{array}$ & $30 \%$ & $22,22 \%$ & $10 \%$ & $30 \%$ & $11,11 \%$ & $0,00 \%$ & $10 \%$ & $16,19 \%$ \\
\hline $\begin{array}{l}\text { Producción y } \\
\text { comercialización de leche }\end{array}$ & $0,00 \%$ & $0,00 \%$ & $0,00 \%$ & $0,00 \%$ & $0,00 \%$ & $0,00 \%$ & $0,00 \%$ & $0,00 \%$ \\
\hline $\begin{array}{l}\text { Industrialización de } \\
\text { lácteos }\end{array}$ & $0,00 \%$ & $0,00 \%$ & $10 \%$ & $0,00 \%$ & $0,00 \%$ & $0,00 \%$ & $0,00 \%$ & $1,42 \%$ \\
\hline $\begin{array}{l}\text { Crianza, desposte y } \\
\text { comercialización de pollos }\end{array}$ & $20 \%$ & $22,22 \%$ & $20 \%$ & $30 \%$ & $22,22 \%$ & $22,22 \%$ & $40 \%$ & $25,23 \%$ \\
\hline $\begin{array}{l}\text { Crianza, desposte y } \\
\text { comercialización de cuyes }\end{array}$ & $0,00 \%$ & $11,11 \%$ & $0,00 \%$ & $0,00 \%$ & $0,00 \%$ & $0,00 \%$ & $0,00 \%$ & $1,58 \%$ \\
\hline $\begin{array}{l}\text { Crianza de ganado vacuno, } \\
\text { porcino }\end{array}$ & $40 \%$ & $0,00 \%$ & $0,00 \%$ & $30 \%$ & $22,22 \%$ & $22,22 \%$ & $30 \%$ & $20,64 \%$ \\
\hline Granjas integrales & $0,00 \%$ & $0,00 \%$ & $0,00 \%$ & $0,00 \%$ & $11,11 \%$ & $11,11 \%$ & $0,00 \%$ & $3,18 \%$ \\
\hline $\begin{array}{l}\text { Emprendimientos de } \\
\text { turismo }\end{array}$ & $0,00 \%$ & $0,00 \%$ & $20 \%$ & $0,00 \%$ & $22,23 \%$ & $22,23 \%$ & $0,00 \%$ & $9,21 \%$ \\
\hline $\begin{array}{l}\text { Emprendimientos de } \\
\text { alimentación y bebida }\end{array}$ & $0,00 \%$ & $11,11 \%$ & $0,00 \%$ & $0,00 \%$ & $11,11 \%$ & $11,11 \%$ & $0,00 \%$ & $4,77 \%$ \\
\hline
\end{tabular}

Fuente: Solis, Quevedo, Mantilla, Neira. Ecuador, 2018 
Tabla Nro. 6 V5: Apoyo Técnico, Financiamiento y Capacitación en Emprendimiento

\begin{tabular}{|l|c|c|c|}
\hline & & Ni & N/C \\
\hline Zhoray Social & $10 \%$ & $88 \%$ & $2 \%$ \\
\hline Matapín & $30 \%$ & $60 \%$ & $10 \%$ \\
\hline Las Américas & $22 \%$ & $72 \%$ & $6 \%$ \\
\hline San Antonio de Paguancay & $17 \%$ & $81 \%$ & $2 \%$ \\
\hline La Primavera & $20 \%$ & $75 \%$ & $5 \%$ \\
\hline Sageo & $10 \%$ & $89 \%$ & $1 \%$ \\
\hline Nuevo Javín & $21 \%$ & $78 \%$ & $1 \%$ \\
\hline Valores promedio & $18,57 \%$ & $77,58 \%$ & $3,85 \%$ \\
\hline
\end{tabular}

Fuente: Solis, Quevedo, Mantilla, Neira. Ecuador, 2018 